\title{
Desenvolvimento local e turismo: uma utopia?
}

\section{Local development and tourism: an utopia?}

\author{
Marcos Pereira Campos, Milton Augusto Pasquotto Mariani, \\ Rosângela Custódio Cortez Thomaz
}

\begin{abstract}
RESUMO
O presente texto foi elaborado com a principal finalidade de buscar ferramentas teórico-conceituais para o entendimento do desenvolvimento local e sua relação com a atividade turística. Vale destacar a importância do estudo de conceitos e temas ímpares para o entendimento do fenômeno do turismo, com destaque para: desenvolvimento, políticas de turismo e localidade. Questão de análise no que se refere aos estudos de desenvolvimento local, neste caso, no turismo, é verificar os elementos fundantes deste processo, ou seja, quais benefícios/malefícios (caso tenham) os sujeitos do turismo podem receber com essa atividade?.
\end{abstract}

PALAVRAS-CHAVE: Localidade; Políticas de Turismo; Endogenização; Utopia.

\section{ABSTRACT}

This paper was elaborated with the main goal of searching for theoretical and conceptual tools to understand the local development and its relation to touristic activities. It is important to mention the importance of studies in concepts and unique topics to development of tourism, with closer attention to: development, tourism policies, and localities. A question of analysis on what refers to local development studies, in this case tourism, is to verify the founding elements of this process, that is, what benefits/detriments (should there be any) can one subjected to tourism receive from such activity?

KEYWORDS: Locality; Tourism Policy; Endogenization; Utopia. 


\section{Introdução}

O turismo vem sendo abordado por muitos autores como a alternativa para os problemas de muitas regiões dos estados do Brasil, bem como um veiculador de atitudes, padrões comportamentais e desenvolvimento.

Vale ressaltar que será entendido como Turismo a definição do Instituto Brasileiro do Turismo - EMBRATUR (1994), onde o mesmo é compreendido como uma atividade gerada a partir dos deslocamentos voluntários e temporários de pessoas para fora dos limites da área ou região em que têm residência fixa, por qualquer motivo, que não o de exercer alguma atividade remunerada no local visitado.

O turismo, no mundo globalizado, apresenta-se em inúmeras modalidades, sob diversas fases evolutivas, que podem ocorrer sincronicamente num mesmo país, em escalas regionais ou locais. Expande-se em nível planetário, não poupando nenhum território nas zonas glaciais, nas cadeias terciárias, até nas regiões submarinas - na cidade; no campo; na praia; nas montanhas; nas florestas; savanas, campos e desertos; nos oceanos, lagos, rios, mares e ares.

O termo "desenvolvimento" é abordado de diferentes formas nos estudos do turismo, seria um equívoco tentar definir uma conceituação puramente instrumental, que pouco acrescentaria a essa discussão. Porém, torna-se importante discutir esse conceito para o entendimento coerente da problemática que envolve os termos acima citados (turismo e desenvolvimento), que para balizar o estudo serão apontadas algumas argumentações que nortearão uma futura análise, fazendo com que esteja sempre aberta a novas contribuições.

Souza (2002) apresenta-nos um quadro importante para a análise do desenvolvimento local, no que se refere aos elementos teórico-conceituais e, bem como, metodológicos relevantes sobre 0 significado do turismo para 0 desenvolvimento (expressa através da seguinte pergunta): quem ganha (ou tende a ganhar) e quem perde (ou pode perder) com a atividade turística?

Vale destacar que o presente artigo foi realizado através de pesquisa bibliográfica em revistas especializadas e livros, cujo temas: Turismo e desenvolvimento local, processo de endogenização, utopia, entre outros. Concomitantemente foi realizado um levantamento desta bibliografia para a elaboração conceitual e definição de marcos teóricos.

\section{Desenvolvimento X Turismo}

Sobre o desenvolvimento da atividade turística, Ouriques (2005) faz uma crítica sobre o estudo desta atividade sob a ótica desenvolvimentista. Para este autor, "os meios políticos e empresariais capturam e vendem o discurso de que o desenvolvimento do turismo é a grande alternativa para o futuro de muitas localidades brasileiras" (OURIQUES, 2005, p. 16).

Outro autor que compartilha com Ouriques (2005) é Castro (1998), onde: 
a "sedução matemática" dos números do turismo tem levado a elucubrações estatísticas - reveladoras de certo grau de emocionalismo de alguns pesquisadores - que sombreiam, empobrecem, mascaram fatos que, supostamente, deveriam contribuir para revelar.

Ainda nesta perspectiva da "sedução matemática", Cruz (2001, p. 08) mostra que:

Os "números do turismo" indicam que a atividade suplantou a indústria bélica, nos últimos anos do século $X X$, em volume de capital transacionado, e que está muito próxima de atingir valores iguais ou superiores àqueles gerados pela indústria petrolífera, primeira no ranking mundial. Estatísticas oficiais mostram, ainda, que a atividade turística apresenta números expressivos, também, no que se refere a deslocamentos de fluxos, à mão-de-obra empregada, à geração de renda etc.

No que se refere às políticas públicas governamentais, o Brasil, segundo Becker (1995), começou a preocupar-se com o turismo na década de 50, período em que profundas transformações se processaram em todo o Brasil, com destaque para o aumento de indústrias no país, com destaque para a indústria de automóveis; aumento das rodovias, bem como, a emergência das classes médias.

Para Becker (2001), a Política Nacional de Turismo existe, orientada para o turismo como vetor de desenvolvimento, tendo sido as primeiras regulações feitas em 1958, ligadas à energia e ao transporte, no período de Juscelino Kubitscheck.

Sobre política de turismo, é apresentado por Beni (2003, p. 178), como:

o conjunto de fatores condicionantes e de diretrizes básicas que expressam os caminhos para atingir os objetivos globais para o turismo do país; determinam as prioridades da ação executiva, supletiva e assistencial do Estado; e facilitam o planejamento das empresas do setor quanto aos empreendimentos e atividades mais suscetíveis de receberem apoio estatal.

Percebe-se então a importância das políticas públicas no desenvolvimento da atividade turística. Não se pode deixar de citar também que a atividade turística é multidisciplinar/transdisciplinar, sendo assim, deve estar interligada a outras políticas públicas (como as da área de transporte, meio ambiente, cultura etc.), para o seu real desenvolvimento, bem como preocupar-se com questões macros, como o desenvolvimento turístico em diferentes escalas (do local, ao global).

Quem corrobora com este tipo de desenvolvimento no turismo é Fortunato e Silva (2001). Para estes autores o desenvolvimento local buscará, através dos sujeitos (sociedade civil organizada, instituições governamentais e cooperação pública) apoio/auxílio aos empreendimentos comunitários buscando, desta forma, que sejam superadas suas limitações de ordem histórica, e que os impossibilitam de 
alcançar seu pleno potencial como indivíduos e como comunidade, para atingir, assim, o bem-estar que tanto almejam.

Em relação a atividade turística, Campos (2007) aponta que o poder público, em todos os níveis de administração, atua na promoção de infraestrutura, na preservação de ambientes, na regulação do uso dos recursos disponíveis, na mediação de interesses entre os diferentes agentes econômicos e entre a população, e na promoção de destinos.

O governo central deve preocupar-se com a política macroeconômica e especificar o peso ou a relevância da atividade turística na economia nacional, estabelecendo os objetivos a serem alcançados e as estratégias utilizadas para alcançar estes objetivos. Cabe também ao governo federal promoção do país no exterior. Ao governo estadual, por sua vez, cabe adaptar a política central a uma realidade mais concreta (...), como também promover o destino no âmbito nacional e internacional. O governo local deve assumir uma das funções mais importantes que é a de gerir o território onde se efetiva a atividade turística (...). Cabe ao poder municipal definir o uso e ocupação do solo, autorizar a instalação de atividades, promover a infraestrutura básica, incentivar as manifestações culturais, dentre outros (FONSECA, 2004, p. 58).

Nota-se, desta forma, a importância da política e do planejamento para o desenvolvimento do turismo. Chevitarese e Mattos (2003) apontam que há necessidade de uma nova concepção política no turismo entendendo a mesma como instrumento de desenvolvimento local, através de um processo de engajamento, participação comunitária e empoderamento.

A ideia da associação do turismo com o de desenvolvimento é para Ouriques (2005) uma falsa contradição, pois acaba utilizando o rótulo do turismo como um grande promotor de emprego para as populações locais, incremento para as receitas municipais, ou seja, acaba a atribuir ao turismo a ideia de uma atividade que traz o desenvolvimento ecologicamente sustentável.

Rodrigues (2001) que trabalha com a ideia de que a atividade turística se torna o novo mito do desenvolvimento em que o que conta é apenas o que pode ser contado (contabilizado). Rodrigues (2000a) em "Desenvolvimento sustentável e atividades turísticas" aponta que a atividade turística se insere no ideário do desenvolvimento no qual o que conta é apenas o sucesso, não inserindo aí os impactos negativos.

Percebe-se que quando se traz à tona o termo desenvolvimento, muitos são os conceitos inerentes a essa palavra, principalmente quando tange à atividade turística.

Portuguez (2002) mostrou-se preocupado em discutir tal problema, pois para este autor, o interesse em mostrar o quanto a ideia de desenvolvimento por meio do turismo e de seus agentes multiplicadores vem sendo difundida de forma inadequada. Para este autor, as localidades receptoras do turismo, devem realmente mobilizar-se tendo em vista ordenar seus processos particulares de conquista da felicidade coletiva, com base não apenas na agregação de renda, mas, sobretudo 
da viabilização de estratégias de promoção da qualidade de vida em âmbito local. Afirma ainda, que muito se tem visto a ideia de desenvolvimento em função do capital, atrelado aos modelos tradicionais de acumulação, que não se incomodam com os custos sociais, nem tampouco ambientais, advindos dos empreendimentos do setor.

O desenvolvimento pode ser entendido como sinônimo de progresso, ampliação qualiquantitativa dos recursos de produção, como observa-se na crítica de Souza (2002, p. 18):

[...] é basicamente, o binômio formado pelo crescimento econômico (mensurável por meio do crescimento do Produto Nacional Bruto [PNB] ou do Produto Interno Bruto [PIB]) e pela modernização tecnológica, em que ambos se estimulam reciprocamente.

A crítica que é feita sobre esta ideia de desenvolvimento, é que não basta um grande aumento do PIB ou do PNB, ou seja, aos ditames político-econômicos, mas bem como ao caráter social do desenvolvimento.

A proposta de uma definição atrelada aos aspectos sociais foi concebida por Rodrigues (1997) que afirmou que o vocábulo desenvolvimento não pode ser empregado como sinônimo de crescimento, nem tampouco regular a distribuição da riqueza, e lembra ainda que a economia não é tudo sem eficácia social, pois o crescimento do PIB não pode ser tomado como referencial único para definir o "desenvolvimento".

Cavalcanti (2001), também trabalha com a distinção entre desenvolvimento e crescimento, pois para este autor, existe uma tendência, quando se fala sobre progresso, a igualar estes dois termos. Isso é o que se quer dizer quando propostas de desenvolvimento são discutidas nos países menos desenvolvidos ou quando se alude, como no Brasil, à necessidade da "retomada do desenvolvimento". Foi Singer (apud ÁVILA et al. 2000) que esclarece a expressão "(...) desenvolvimento sem crescimento (...)" - embora o contexto em que ela se situa, não se restrinja única e exclusivamente a desenvolvimento econômico:

O primeiro corolário da distinção entre desenvolvimento e crescimento é que o crescimento é visto como um processo expansão quantitativa, mais comumente observável nos sistemas relativamente estáveis dos países industrializados, ao passo que o desenvolvimento é encarado como um processo de transformações qualitativas dos sistemas econômicos prevalecentes nos países subdesenvolvimentos [...]. O desenvolvimento é o processo de passagem de um sistema a outro (SINGER apud ÁVILA et al. 2000, p. 22).

Souza (2002) entende desenvolvimento como um processo de superação de problemas sociais, em cujo âmbito uma sociedade se torna, para seus membros, mais justa e legítima.

Como desenvolvimento, Pereira (1985) entende como um processo de transformação econômica, política e social, através da qual o crescimento do padrão de vida da população tende a tornar-se um processo social global, em que as 
estruturas econômicas, políticas e sociais de um país sofrem contínuas e profundas transformações.

Pereira (1985), ainda vai mais longe, afirmando:

Não tem sentido falar-se em desenvolvimento apenas econômico, ou apenas político, ou apenas social. $\mathrm{Na}$ verdade, não existe desenvolvimento dessa natureza, parcelado, setorializado, a não ser para fins de exposição didática (...) O desenvolvimento, portanto, é um processo de transformação global (PEREIRA, 1985, p. 30).

No turismo não seria diferente, pois todos os aspectos devem ser considerados para que possamos fazer uma análise acerca do termo "desenvolvimento turístico". Não podemos considerar um espaço turístico como desenvolvido se apenas uma parcela da localidade está se beneficiando.

Outro conceito de desenvolvimento é feito por Banducci Jr. e Moretti (2001), onde o turismo só passará a ser considerado motor de desenvolvimento quando houverem ações estatais para a construção de infraestrutura: aeroportos, rodoviárias, avenidas, estradas, edifícios etc.

Esta definição está relacionada somente à infraestrutura e aos insumos turísticos, porém devemos encarar que a infraestrutura que um município, região, estado, ou até mesmo país recebe, muitas vezes não são restritos ao uso da atividade turística. Por exemplo, para que o turismo se instale numa localidade, fazse necessário redes de comunicação, redes de saneamento básico, entre outros, entretanto estas infraestruturas não são reservadas somente para o cliente do turismo - o turista, ficando também para o uso dos autóctones/comunidade local.

Outro ponto a ser destacado em relação a definição de Banducci Jr. e Moretti (2001), é que também, de forma indireta outras áreas são influenciadas com o avanço do turismo, como por exemplo o setor de construção civil, setor de alimentação e bebidas (restauração) entre outros.

O que vale ressaltar é a busca de melhoria na qualidade de vida, pois todo indivíduo deseja ser feliz, viver uma longa vida, alcançar a plena realização de si próprio, desta forma o desenvolvimento pode levar a tais objetivos, sendo que este termo não esteve presente na definição de Banducci Jr. e Moretti (2001).

Ainda no contexto da "qualidade de vida", Cavalcanti (2001) afirma, "que não é necessário se aumentar a posse de bens para que uma pessoa se sinta mais feliz. Sem embargo, a possibilidade de se ter mais e mais de cada coisa converteu-se no fim supremo do progresso" (CAVALCANTI, 2001, p. 14).

O tema qualidade de vida está presente em muitos conceitos, como o de Rodrigues (2000) e Cavalcanti (2001), desta forma não podemos excluir a ideia do foco humano no tema desenvolvimento.

Martins (2002), aponta que a atual tendência em se pensar e planejar o desenvolvimento é dotá-lo de um caráter mais humano, no sentido de considerar o homem simultaneamente como sujeito e beneficiário.

A ideia de desenvolvimento em escala humana, em que as necessidades humanas sejam atendidas desde o começo e durante todo o processo de 
desenvolvimento, é proposta por Max-Neef et al (1994), ou seja, que "a realização das necessidades não seja só a meta, mas sim o próprio motor do desenvolvimento". (MAX-NEEF et al, 1994, p. 60).

Nesta perspectiva, vale apontar a importância dos sujeitos envolvidos ativamente na prática do desenvolvimento, tal como preconizou Gonzalez:

A presença da prática humana como protagonista da ação desenvolvimento. Não se tratando somente como um mero suporte de ações humanas, mas de um agente que de acordo com suas potencialidades e limitações, pode favorecer ou dificultar 0 desenvolvimento (GONZALEZ apud MARTINS, 2002, p. 54).

O cenário da ação humana - em que o desenvolvimento se configura na escala espacial, ou base territorial, é o cenário de representações e de práticas humanas, nas quais se localizam os desafios $e$ as potencialidades do desenvolvimento.

Nos estudos de Coriolano e Silva (2005) podemos perceber que as atividades humanas têm como pressuposto fundamental a comunidade, e o território, espaços de pequena dimensão que oferecem condições para a solidariedade orgânica, porque seu principal objetivo é atingir setores marginalizados, de situar o homem como principal beneficiário do processo e respeitar seus direitos.

A partir destes pressupostos, entenderemos o desenvolvimento na perspectiva de Azevedo e Chicico (2013), ou seja, em que o desenvolvimento independentemente da sua acepção espacial (rural ou urbano) será exigida uma consideração simultânea das diversas dimensões constituintes das relações sociais (economia, política, cultura) e, também do espaço social e natural, significa o desenvolvimento das potencialidades humanas e, bem como, a consolidação pela cidadania.

Sobre a associação do tema turismo e desenvolvimento, a qualidade de vida dos atores/agentes locais é apresentado por Souza (2002), que trabalha a contribuição do turismo para o desenvolvimento da localidade.

\section{Desenvolvimento da localidade}

A busca por uma definição meramente quantitativa, respaldada apenas em indicadores pré-estabelecidos (como por exemplo, renda, grau de instrução, condições de moradia, etc.) mostra-se insuficiente, pois cada indivíduo possui uma visão em relação com o termo qualidade.

Deste modo, do ponto de vista histórico Gómez-Vela e Sabeh (2003) esclarece que é muito antigo o interesse por qualidade de vida, mas que 0 surgimento do conceito como tal e a preocupação pela avaliação sistemática e científica do mesmo é relativamente recente.

Para a Organização Mundial da Saúde (OMS apud SILVA et al., 2005) "qualidade de vida é "a percepção pessoal de um indivíduo acerca de sua situação de vida, dentro do contexto cultural e de valores em que vive e em relação com seus objetivos, expectativas, valores e interesses". A expressão passou a definir como 
conceito integrador que compreende todas as áreas da vida (caráter multidimensional) e faz referência tanto a condições objetivas como a componentes subjetivos.

A associação do termo qualidade de vida atrelada ao desenvolvimento do turismo é discutido por muitos autores com o título de desenvolvimento local ou com base local, em que tomar-se-á como referencial teórico para este estudo. como um:

Sobre desenvolvimento local, Cavaco (2002, p. 98) empregou a expressão

processo em que as localidades, munidas de seus recursos mais variados, criam oportunidades de promoção do bem-estar coletivo, implementando atividades que de alguma forma dinamizem a economia em pequena escala [...] este tipo desenvolvimento, assenta na revitalização e diversificação da economia, capaz de fixar e atrair população, de ocupar a população potencial ativa, com êxito econômico, profissional e social, de valorizar produções, de renovar as habitações e as aldeias e de assegurar melhores condições de vida.

Já Para Buarque (2000) desenvolvimento local, apresenta como sendo um processo endógeno registrado em pequenas unidades territoriais e agrupamentos humanos capaz de promover o dinamismo econômico e a melhoria da qualidade de vida da população.

A endogenização exposto por Buarque, trata-se de um processo de interiorização, ou seja, um desenvolvimento no âmbito/seio da própria comunidade. Desta forma, percebemos que os questionamentos apontados por Souza (2002) quanto a quem ganha (ou tende a ganhar), conforme apresentado na introdução deste texto, está intrinsecamente ligado com o processo de endogenização, no sentido de empoderamento da comunidade/localidade.

Sobre o desenvolvimento endógeno, Cavaco (2002), aponta que tal desenvolvimento depende não tanto da combinação ótima de recursos e fatores de produção como de fazer aflorar e mobilizar recursos e capacidades escondidas, dispersas ou mal utilizados.

Já segundo Nóvoa (apud ÁVILA, 2000), o desenvolvimento endógeno não significa, todavia, que as comunidades locais se isolem em relação aos processos exteriores ou de âmbito nacional; pelo contrário, as interações com o meio envolvente tenderão a reforçar-se, no quadro de uma internalização (ou de uma localização) desses processos.

Desenvolvimento local é a organização comunitária em torno de um planejamento para o desenvolvimento, por uma perspectiva de construção social. Para Botelho e Fraga (2015, p. 58):

O desenvolvimento local pressupõe criatividade e inovação social na identificação das necessidades e busca por soluções, por meio da participação social dos sujeitos envolvidos, associando qualidade de vida, sustentabilidade econômica das iniciativas de turismo locais e proteção do patrimônio natural e histórico-cultural. 
A discussão sobre o tema "local" faz-se necessário quando se quer entender o desenvolvimento, pois especializar tal tema, seria uma das formas de se entender todo o processo.

Sobre "local", Martins (2002) refere-se à escala das inter-relações pessoais da vida cotidiana, que sobre uma base territorial constroem sua identidade. O lugar é essa base territorial, o cenário de representações e de práticas humanas que são o cerne de sua singularidade; o "espaço da convivência humana", na qual se localizam os desafios e as potencialidades do desenvolvimento.

Uma problemática do termo desenvolvimento local está no entendimento do conceito local. Para Martins (2002, p. 54):

A escala local, é dada como aquela que permite a eficácia das ações e um melhor acompanhamento dos resultados, está associado ao fracasso de um modelo de desenvolvimento pautado na industrialização a qualquer custo, no consumo de massa, em altíssimos custos ambientais e sociais, viabilizado por ampla disponibilidade de capitais.

O problema da escala, já foi apresentado por Castro (1998), em que, embora ainda pouco discutido, começa a ir além de uma medida de proporção de representação gráfica do território, ganhando novos contornos para expressar a representação dos diferentes modos de percepção e de concepção do real.

O local, para Benevides (1998), deve ser referenciado não somente no sentido valorativo da escala espacial - small is beautiful - mas é representado como alternativa ao padrão dominante de desenvolvimento, como um espaço que, por estar à margem desse padrão, preserva relações comunitárias pouco hierarquizadas e enseja a continuidade de formas mais ambientalmente sustentáveis de produzir, submetidas às culturas de intercâmbio material tradicional entre sociedade e natureza.

O adjetivo local no contexto da expressão desenvolvimento local assume conotações muito mais diversificadas e abrangentes, como por exemplo; para Lazarte (apud ÁVILA, 1999, p. 26):

(...) la revisión propuesta, nos lleva a reivindicar el ámbito de lo local, como un espacio más concreto de participación social en el proceso, como uma unidade de análisis, planificación y acción, capaz de relevar y activar un conjunto de potencialidades no apreciadas por el planificador tradicional y de atender un igual número de demandas insatisfechas através de mecanismos apropriados al contexto y escala de las mismas, aportando de esta manera dentro de un esfuerzo sinérgico de la región y el país.

Martins (2002) entende por espaço local, o "definido por um conteúdo ecologicamente dinâmico e historicamente elaborado e experimentado pelas pessoas que nele mora". 
No que se refere ao fenômeno do turismo, o termo local, do conceito desenvolvimento local, está ligado ao processo de endogenização, como apresentado por Gobierno Vasco (1994):

Porém para o turismo, o termo local está mais ligado com a concepção de desenvolvimento que valoriza o local como referência territorial e que ganha força, na Europa, a partir dos anos 80, quer aproximar-se das pessoas, apoiar-se na solidariedade comunitária, instrumentalizar a comunidade, envolvendo-a efetivamente na superação dos problemas e na promoção do desenvolvimento endógeno (GOBIERNO VASCO, 1994, p. 52).

Interessante notar que existem outras possibilidades a serem valorizadas no turismo, conforme preconiza o estudo de Coriolano e Silva (2005), bem como Portuguez et al. (2006), que apontam para o aproveitamento das externalidades, priorizando a infraestrutura macia - o chamado capital social - trabalhando o conhecimento tácito - a cultura, o sentimento de pertença, a intuição, os valores locais, a emoção, dentre outros mais voltados ao homem. Esta ideia nos remete não apenas à economia, mas a toda uma filosofia voltada às pessoas e aos lugares.

No que se refere a população/morador do local, ou "ator local", como tem-se denominado principalmente no turismo, sendo sinônimos de autóctone, empresário do turismo, funcionários, ou seja, todo aquele que faz parte do "fazer turístico", este deve ser considerado como sendo o sujeito da ação do turismo, responsável e protagonista de tal atividade. Pois percebemos que este "ator", por muito tempo vem sendo tratado como objeto do turismo, ou seja, uma peça fácil de ser manipulada ou um simples figurante do sistema.

Ávila (2000) mostra-nos, que parece mais lógico o emprego do termo "agente" ao invés de "ator", na língua corrente no Brasil, para designar pessoa que exerça ou pretenda exercer função estratégica de implementação do desenvolvimento local, não importando que seja de fora ou de dentro da comunidade localizada a que se destinem os seus préstimos.

Para Ávila (2000) ainda, o uso do termo "agente de desenvolvimento local" tem a finalidade, a função e o compromisso exclusivos de agenciador/intermediador (do verbo agenciar) na direção comunidade $\rightarrow$ desenvolvimento (e não na inversa: desenvolvimento $\rightarrow$ comunidade), ou seja, trabalhando e influenciando para que a comunidade mesma desabroche capacidades, competências e habilidades de desenvolvimento, sem a imediatista pretensão de querer levar o desenvolvimento para a comunidade ou de querer erigir iniciativas desenvolvimentistas na comunidade, que não fluam de seu real estágio de cultura, de condições e de política de progresso coletivo.

Segundo Ávila (2000, p. 73):

Há uma distinção entre o 'desenvolvimento 'no local' e o 'desenvolvimento local', sendo que no primeiro, os agentes externos são os promotores do desenvolvimento e a comunidade apenas se envolve participando; já no segundo, a própria comunidade assume o agenciamento do seu desenvolvimento e os agentes externos são os que se envolvem participando. 
Outro item a ser destacado no tema "desenvolvimento local" é pensar que não basta somente oferecer bem-estar, qualidade de vida entre outros benefícios para a comunidade, se não oferecer a ela a capacidade de participação do processo - no caso específico: o turismo. A participação na escala local proporcionará a efetivação, a continuidade e a sustentabilidade do desenvolvimento.

Sobre participação, Martins trabalha com a ideia de que:

Além da tomada de consciência, a formação de um senso crítico e a sensibilidade. Por certo, são estes requisitos difíceis de serem obtidos, sobretudo quando não estimulados e mesmo sufocados por períodos de pouca ou nenhuma democracia (MARTINS, 2002, p. 52)

Martin (1997) chama a atenção para alguns pontos desse desenvolvimento macro, são eles: a dimensão local que constitui o nível geográfico idôneo, tempo para a execução de ações, a abertura do lugar ao mundo e a modernidade, os valores locais, como o patrimônio, a história e a cultura, os produtos locais (naturais e econômicos) devem ser divulgados, o município como referência de unidade de análise, os autóctones como protagonistas das dinâmicas sociais abertos aos pactos e as parcerias que levem ao desenvolvimento.

No que diz respeito ao desenvolvimento específico da atividade turística, os governos nas esferas federal, estadual e municipal vêm desenvolvendo estratégias de planejamento para dinamizar essa atividade, como forma de viabilizar o desenvolvimento econômico e social do país. Entre essas estratégias destaca-se o Programa Nacional de Municipalização do Turismo (PNMT).

O PNMT surge conforme Lei $\mathrm{n}^{0}$ 8.490, de 19 de novembro de 1992, e regulamentado pela Portaria no 130, de 30 de março de 1994, baixada pelo ministro da Indústria, Comércio e Turismo, o objetivo principal do programa seria, de acordo com as suas diretrizes, que de acordo com a (EMBRATUR, 2001), visava

Fomentar o desenvolvimento turístico dos municípios, com base na sustentabilidade econômica, social, ambiental, cultural e política, descentralizando as ações de planejamento, coordenação, execução, acompanhamento e avaliação, motivando os segmentos organizados do município a participar da formulação e da cogestão de um plano de desenvolvimento sustentável do turismo.

De acordo com Mariani (2006), os objetivos específicos do PNMT foram os seguintes:

- Conscientizar e sensibilizar a sociedade para a importância do turismo como instrumento de crescimento econômico, de geração de emprego, de melhoria da qualidade de vida da população e de preservação de seu patrimônio natural e cultural.

- Descentralizar as ações de planejamento, coordenação, execução, acompanhamento e avaliação, motivando os segmentos organizados do município a participar da formulação e da cogestão do Plano de Desenvolvimento Sustentável do Turismo. 
- Disponibilizar aos municípios brasileiros com potencial turístico, as condições técnicas, organizacionais e gerenciais para o desenvolvimento das atividades turísticas.

- Estimular o fortalecimento das relações dos diferentes níveis do poder público com a iniciativa privada, visando ao estabelecimento de parcerias para discutir os problemas e buscar soluções, junto à comunidade, em benefício da atividade turística.

- Elevar os níveis de qualidade, de eficiência e de eficácia da prestação dos serviços voltados para as atividades turísticas.

Cruz (2001) e Mariani (2006) afirmam que o quadro evidencia a existência de barreiras concretas à efetivação de um plano de municipalização do turismo na região: municípios política e economicamente enfraquecidos, subordinados a um poder público estadual altamente centralizador.

\section{O desenvolvimento do local e as formas de apropriação pelo turismo no espaço rural}

A política de municipalização do turismo poderia vir a se constituir em fator de fortalecimento dos municípios turísticos do estado. Seus resultados não devem, porém, ser alcançados em curto prazo. As mudanças estruturais necessárias à sua efetivação são complexas e dependem de alterações profundas, que envolvem a própria formação sócio-cultural-econômica da localidade.

Percebe-se que a proposta do PNMT veio ao encontro da temática da nova ruralidade, quando incorpora as populações rurais e pesqueiras nesse novo cenário, que se desenha para o meio rural, como exemplo, através da criação de conselhos, pois pressupõe a participação das populações locais como sujeitos do desenvolvimento local, como preconiza tal processo, ou seja reforçando os aspectos endógenos em detrimento dos exógenos, bem como, fazendo emergir com força a preocupação com o ambiental e o local, não somente em caráter geográfico como sociais.

O que vale notar, principalmente depois da discussão à cerca do local, é afirmar que o município objeto principal do PNMT, é a instância mais adequada para a gestão do turismo. A possibilidade do estudo do desenvolvimento do turismo na escala local também se dará na esfera espaço rural.

A discussão que deve ser feita é no que tange ao desenvolvimento do turismo com base local nos diferentes espaços rural e urbano. Para este trabalho faz-se necessário somente pensar no estudo do turismo no espaço rural, em que será adotado como sendo o preconizado por Bovo (2006) em seu estudo "O ecoturismo não deve ser pensado como turismo rural, mas sim como opção inteligente de turismo no meio rural'.

O termo desenvolvimento local e turismo no espaço rural é objeto de estudo para Cavaco (1996). Esta autora aborda as estratégias de desenvolvimento local como o alargar do conceito de desenvolvimento rural, tomando-se freqüentes as referências ao desenvolvimento endógeno (mobilização dos próprios recursos), ascendente (protagonismo dos agentes locais), autocentrado (centrado nas 
necessidades próprias das comunidades), sustentável, ecodesenvolvimento, cujo sentido está parcialmente incluído no de desenvolvimento local.

Cruz (2001), afirma que "o turismo em espaço rural nada mais é que a apropriação, pelo turismo de mais uma dimensão do espaço geográfico".

Bovo (2006, p. 52), é mais analítico, em afirmar que:

O espaço rural é essencialmente o conjunto dinâmico de três elementos - o modo de vida, a identidade local e a natureza - e pode ser caracterizado por um espaço onde exista uma presença significativa da natureza e a atividade produtiva esteja vinculada diretamente, indiretamente ou em equilíbrio com o meio natural, tendo predomínio da atividade produtiva primária, mas sendo possível a existência de atividades secundárias.

Através desta definição podemos entender como se dá o turismo no espaço rural, principalmente após o autor ter aberto a possibilidade durante a sua apresentação - existência de "atividades secundárias" em que o turismo encaixa-se perfeitamente.

Como já foi vivenciado por Campanhola e Silva (1999) em estudo e como existe esta problemática acerca da definição dos termos relacionados aos diferentes segmentos do turismo, será utilizado para esta pesquisa o termo "turismo no espaço rural”, que contemplará todos os tipos de turismo já mencionados: pesca, ecológico, ecoturismo e rural.

Considera-se Turismo no Espaço Rural ou em áreas rurais todas as atividades praticadas no meio não urbano, que consiste de atividades de lazer no meio rural em várias modalidades definidas com base na oferta: turismo rural, agroturismo, turismo ecológico ou ecoturismo, turismo de aventura, turismo de negócios, turismo de saúde, turismo cultural, turismo esportivo, atividades estas que se complementam ou não (GRAZIANO DA SILVA et al., 2000)

Almeida (2003) também verificou uma grande variedade de termos ao se referir a atividade turística na área rural. Para este autor há uma variedade de termos que procuram classificar o turismo no espaço rural e colocar vários outros tipos de turismo como atividades inseridas no espaço rural, tais como: turismo verde, turismo rural, agroturismo, turismo ecológico, turismo cultural, turismo social, turismo de saúde, turismo desportivo, turismo de aventura, turismo de natureza.

Para Rodrigues (2001) ,a importância de ressaltar que a atividade turística rural não deva ser interpretada somente observando o rural como contraponto ao urbano, sendo importante a consideração de pelo menos alguns fatores fundamentais, tais como: processo histórico de ocupação territorial, a estrutura fundiária, características paisagísticas regionais, estrutura agrária, com destaque para as relações de trabalho desenvolvidas, atividades econômicas atuais, características de demanda e tipos de empreendimentos.

Nesse contexto, Benevides (2002, p. 25), mostra que: 
O turismo alternativo se constituiria como uma mediação possível de dar alguma possibilidade de geração local de emprego e renda, que, por sua vez, constitui o braço economicista da ideologia do localismo.

O autor, afirma que o desenvolvimento local, deverá ser concebido como um estilo contraposto às tendências e aos padrões dominantes, e que as principais preocupações e orientações estariam presentes:

- A manutenção da identidade cultural dos lugares, como próprio fator de atratividade turística, e o estabelecimento de um maior intercâmbio e integração entre as populações hospedeiras e os visitantes;

- A construção de uma via democrática para o desenvolvimento de certas localidades, articulada pelo turismo como fator estruturante da valorização das suas potencialidades ambientais e culturais, com a participação da população local na condução ativa desse processo. Dadas suas características socioeconômicas, essa participação ativa só seria viável em "projetos" turísticos de pequeno porte e com baixos custos de instalação e de operação;

- Estabelecimento de pequenas escalas de operação e baixos efeitos impactantes dos investimentos locais em infraestrutura turística, ou mesmo nenhuma transformação adicional destes espaços, tendo em vista que estes estariam subordinados aos parâmetros da conservação do meio ambiente e da rusticidade local, num processo de "valorização sem transformação" dos elementos "naturais", como fundamento da atratividade turística.

Percebe-se que esta proposta de um turismo voltado ao desenvolvimento local, apresentada por Benevides (2002), principalmente no que tange ao turismo alternativo, representa de certo modo: conservação/preservação ambiental. identidade cultural, geração de ocupações produtivas e de renda, desenvolvimento participativo e principalmente qualidade de vida para os atores do turismo (desde 0 empresário ao funcionário do empreendimento turístico).

A história de muitas regiões do mundo, tem no turismo no espaço rural uma nova opção para o incremento econômico da localidade, não somente isso a fixação do homem no espaço rural é um fator especialmente notado quando se trata em desenvolvimento local, pois quem mais gostaria em desenvolver a localidade se não o autóctone?

Rodrigues (2000) afirma que o turismo desempenha um papel importante, pois, quando desenvolvido em espaços rurais vem constituindo-se em uma alternativa para fortalecer o desenvolvimento local e principalmente interiorizar a atividade turística, hoje concentrada nos municípios litorâneos e durante o verão, fator este que torna a atividade extremamente sazonal.

Campanhola e Silva (1999) reforçam tal afirmativa, quando se referem ao turismo no espaço rural como uma forma de valorização do território, pois ao mesmo tempo em que depende do espaço local e rural para o seu sucesso, contribui para a proteção do meio ambiente e para a conservação do patrimônio natural, histórico e cultural. 
Para Pellin (2006), o turismo no espaço rural pode se constituir em um dos vetores do desenvolvimento local, desde que:
a) as decisões sejam tomadas no âmbito local,
b) haja controle dos processos de desenvolvimento por atores locais,
c) as comunidades locais se apropriem dos benefícios gerados. $O$ turismo no espaço rural deve, antes de tudo, ser um turismo local, de território, gerido pelos próprios residentes (PELLIN, ibid, 129).

Silva et al. (2000) no seu estudo "Turismo em áreas rurais: suas possibilidades e limitações no Brasil", utilizou o termo "turismo em áreas rurais" para englobar não só aquelas atividades de serviços não-agrícolas, tradicionalmente denominadas de "turismo rural ou agroturismo", como também as de lazer realizadas no espaço rural, denominadas de turismo ecológico ou "ecoturismo", turismo de negócios e turismo de saúde. O autor afirma que é importante fazer essa distinção, porque em geral, as atividades ligadas a outras modalidades de turismo que não o agroturismo, são realizadas em determinadas regiões que, por usar condição própria, possuem atrações, despertando o interesse e a curiosidade das pessoas.

O turismo no espaço rural e a palavra desenvolvimento rural são discutidos por muitos autores como sendo uma utopia. Conforme título deste capítulo e tomando emprestado o texto de Ávila (2000), no tocante à hipótese de que o desenvolvimento local seja tachado de utopia, este autor afirma que observando o termo desenvolvimento, encerra dois sentidos possíveis: um pejorativo (depreciativo), comumente utilizado na linguagem corrente, e outro extremamente positivo quando inserido em contexto técnico de prospecção (planejamento). Ambos os sentidos são oriundos da própria etimologia grega da palavra utopia: OU (prefixo de negação ou exclusão) + TOP (raiz do substantivo TÓPOS que significa lugar) + ÍA (sufixo nominal que designa qualidade ou estado de coisas ao termo que ajuda a compor), resulta daí, portanto, que utopia pode se referir:

a) a um estado imaginário ou fantasioso de coisas sem condições de se situarem ou localizarem no tempo e no espaço (sentido pejorativodepreciativo)

b) a um estado bom, desejado e por vezes até necessário de coisas ainda não situadas no tempo e no espaço, mas possíveis de se situarem tão logo ou à medida que surjam ou se criem as condições para tanto (sentido positivo).

Seja na hipótese "a" ou "b", ou seja, no sentido pejorativo-depreciativo e/ou no sentido positivo, respectivamente, serão aplicados, também por duas categorias de analistas, a todo o teor conceitual do desenvolvimento local enfocado neste estudo.

Com tudo o que foi exposto, percebe-se que o verdadeiro desenvolvimento local implica de certa forma na formação e educação da própria comunidade, no que tange aos aspectos culturais, capacidades, competências e habilidades.

Verificou-se também, que a busca para o atendimento deste tipo de desenvolvimento - (desenvolvimento local), na perspectiva do turismo, deve partir do entendimento e do conhecimento do território. Deve-se, assim, priorizar as questões espaciais, históricas e sociais da localidade. A relação do planejamento na 
gestão do espaço e dos negócios, deverão ser a cerne para a busca de um turismo com princípios do desenvolvimento local.

\section{Considerações finais}

Se o turismo pode proporcionar/auxiliar o desenvolvimento local, é importante entender então como acontece tal processo, principalmente no que tange aos aspectos inerentes a apropriação, produção e consumo do espaço, transformando em um território turístico.

Podemos perceber que o turismo pode vir a ser um potencializador para 0 desenvolvimento de uma localidade. Verificamos, também, que se faz necessário compreendermos quem são os sujeitos envolvidos neste processo, bem como, de que forma eles estão estruturados.

Quando se trata dos sujeitos da estrutura do turismo, com destaque para sociedade civil organizada, instituições governamentais e cooperação pública, devemos considerar em especial os elementos endógenos da localidade onde está sendo desenvolvida a atividade turística.

Vale destacar que as localidades devem estar articuladas na ótica global, sendo este o grande desafio para a manutenção deste modelo de desenvolvimento.

Os grandes entraves para a real implementação do modelo de desenvolvimento local, seriam os interesses econômicos do capital global, pois, junto a ele, teremos as posturas, que de certa forma conduziriam a comportamentos egoístas, oportunistas, competitivos e individualistas, que nada contribuiriam com a lógica que se apregoa a organização comunitária do desenvolvimento local.

Desta forma o turismo deve ser compreendido também em uma perspectiva humanista, não considerando somente o positivismo econômico, tão recorrente na sociedade capitalista.

\section{Referências bibliográficas}

ALMEIDA, J.A.; FROEHLICH, J.M.; RIEDL, M. (orgs.) Turismo Rural e Desenvolvimento Sustentável. Campinas-SP: Papirus, 2000.

ALMEIDA, N.P. Segmentação do turismo no Pantanal sul-mato-grossense. UCDB. (Dissertação). Campo Grande. 2003.

ARAÚJO, A.P.C. Pantanal: Um espaço em transformação. UFRJ. (Tese). Rio de Janeiro. 2006.

ÁVILA, V.F. et al. Formação educacional em desenvolvimento local: relato de estudos em grupos e análise de conceitos. Campo Grande. Ed. UCDB. 2000.

AZEVEDO, F.F.; CHICICO, F.J. Turismo de base local no distrito de Dondo (Moçambique): discutindo fatores de sustentabilidade. Revista Brasileira de Ecoturismo, São Paulo, v.6, n.2, mai/jul-2013, pp.458-481.

BANDUCCI JÚNIOR, A.; MORETTI, E. C. (org.). Qual Paraíso? Turismo e Ambiente em Bonito e no Pantanal. UFMS. Campo Grande. 2001. 
BECKER, B.K. Políticas e planejamento do turismo no Brasil. Caderno Virtual do Turismo. Vol. 1, $\mathrm{N}^{\circ} 1$ (2001). [on line]. Disponível na internet, via < http://scholar.google.com.br/scholar?hl=pt-BR\&q=caderno+virtual+do+turismo++Becker\&lr=\&as ylo=> acessado dia 26 de agosto de 2006.

BECKER, B.K. Levantamento e avaliação da política federal de turismo e seu impacto na região costeira. Brasília: PNMA, 1995.

BENEVIDES, I.P. Para uma Agenda de discussão do turismo como fator de desenvolvimento local. In: RODRIGUES, A.B. (org.) Turismo Desenvolvimento Local. 3aㅡ Ed. HUCITEC. São Paulo, 2002.

BENI, M.C. A política do turismo. In: TRIGO, L. G. G. (org.). Como aprender, como ensinar. Vol. 1. 3ª edição. São Paulo. SENAC. 2003.

BOTELHO, E.S.; FRAGA, C. Planejamento e Desenvolvimento Local do Turismo: um Estudo sobre Ferrovia, Turismo e Meio Ambiente no Estado do Rio de Janeiro. Anais Brasileiros de Estudos Turísticos - ABET, [S.I.], p. 55-63, dez. 2015. ISSN 2238-2925. Disponível em: <https://abet.ufjf.emnuvens.com.br/abet/article/view/2911/2236>. Acesso em: 10 ago. 2016.

BOVO, C.E.O. Associativismo - o melhor caminho para o fortalecimento do turismo em espaço rural. In: Anais do $5^{\circ}$ Congresso Brasileiro de Turismo Rural Propriedades, comunidades e roteiros no Turismo Rural. Piracicaba. SP. FEALQ. 2005.

BOVO, C.E.O. O ecoturismo nao deve ser pensado como turismo rural, mas sim como opção inteligente de turismo no meio rural. In: PORTUGUEZ. A. P. (org) et al. Turismo no espaço rural: enfoque e perspectivas. São Paulo. ROCA. 2006.

BRASIL. Comissão Técnica. Programa Ecoturismo - Versão preliminar, 1991. Grupo de Trabalho Interministerial em Ecoturismo: MICT/MMA/EMBRATUR/ IBAMA/Empresários/Consultores. In: Diretrizes para uma política nacional de ecoturismo. Brasília: EMBRATUR/IBAMA, 1994.

BRASIL, Ministério do Turismo. Diretrizes para o Desenvolvimento do Turismo Rural no Brasil. 2004. Disponível em: <http://www.turismo.gov.br> Acesso em: 20 de julho de $2001 .$.

BUARQUE, S. Metodologia e Técnicas de Construção de Cenários com Foco Microrregional. Recife: IPEA, junho, 2000.

CAMARGO, E.I. Políticas Públicas para o Turismo e suas implicações no ordenamento territorial de Bonito - MS . UFMS (Dissertação - Geografia). Aquidauana/MS. 2005.

CAMPANHOLA, C.; SILVA, J.G. Panaroma do turismo no espaço rural brasileiro: nova oportunidade para o pequeno agricultor. In: OLIVEIRA, C. (org.). Anais do $1^{\circ}$ Congresso Brasileiro de turismo rural: turismo no espaço rural brasileiro. Piracicaba. 1999.

CAMPANHOLA, C. ; SILVA, J.G. O agroturismo como nova fonte de renda para o pequeno agricultor brasileiro. In: ALMEIDA, J.A.; RIEDL, M (orgs.) Turismo Rural: ecologia, lazer e desenvolvimento. Bauru. Edusc. 2000. 
CAMPOS, M.P. À sombra do Pequi, vislumbrando os aguapés: desenvolvimento local, território e turismo no Pantanal do rio Aquidauana- MS. Dissertação de Mestrado. Universidade Federal de Mato Grosso do Sul. Programa de pósgraduação Mestrado em Geografia, Aquidauana. 2007.

CASTRO, I. E. de. Turismo e ética. In: CORIOLANO, L. N. M. T. (org) Turismo com ética. Fortaleza: UECE, 1998.

CAVACO, C. Turismo rural e desenvolvimento local. In: RODRIGUES, A.B. Turismo e Geografia: reflexões teóricas e enfoques regionais. 2.ed. São Paulo: Hucitec, 2001.

CAVALCANTI, C. Desenvolvimento e Natureza: Estudos para uma sociedade sustentável. 3를. Ed. Cortez Editora. Pernambuco, 2001.

CHEVITARESE, L.; MATTOS, F.F. "Participação": utopia ética pósmoderna para o turismo sustentável. In: TREVIZAN, S.D.P. (Org.). Comunidades sustentáveis a partir do turismo com base local. Ilhéus: EDITUS, 2006.

CORIOLANO, L.N.M.T.; SILVA, S.C.B M. Turismo e Geografia: abordagens críticas. Fortaleza. Ed. da UECE. 2005.

CRUZ, R.C.A. Política de Turismo e Território. 2ª Ed. São Paulo. Contexto. 2001.

FONSECA, M.A.P. Políticas públicas espaço e turismo: uma análise sobre a incidência espacial do Programa de desenvolvimento do Turismo no Rio Grande do Norte. Rio de Janeiro: UFRJ/PPGG, 2004. (Tese de doutorado).

FORTUNATO, R.A.; SILVA, L.S. Os conflitos em torno do turismo comunitário na Prainha do Canto Verde (CE). Revista Brasileira de Ecoturismo, São Paulo, v.6, n.1, jan/abr-2013

GÓMEZ-VELA, M.; SABEH, E.N. Calidad de vida: evolución del concepto y su influencia em la investigación e la prática. Univerdad de Salamanca. Disponível em <http:// www.3usal.es/inico/invesinico/calidad.htm > Acessado em 15/08/2006.

GRAZIANO DA SILVA, J. et al. Turismo em áreas rurais: suas possibilidades e limitações no Brasil. In: ALMEIDA, J.A. et al. (Org.). Turismo Rural e Desenvolvimento Sustentável. Campinas-SP: Papirus, 2000.

MARIANI, M.A.P; GONÇALVES, H.C. Proposta de implementação de um programa de Educação Ambiental para o setor de turismo na sub-bacia do Rio Miranda (MS). In: PORTUGUEZ; A.P. (org) et al. Turismo no espaço rural: enfoque e perspectivas. São Paulo. ROCA. 2006.

MARTÍN, J.C. Los retos por una sociedad a escala humana: el desarrollo local. In: SOUZA, M.A. Metrópole e gobalização: conhecendo a cidade de São Paulo. São Paulo: CEDESP, 1999. p. 169-177.

MARTINS, S.R.O. Desenvolvimento Local: questões conceituais e metodológicas. INTERAÇÕES - Rev. Internacional de Desenvolvimento Local. UCDB, Vol. 3, N.5, p.51-59, Campo Grande. Set. 2002

MAX-NEEF, M. et al. Desarollo a escala humana. Barcelona: Nordean-Comunidad, 1994 
MORETTI, E.C.; RODRIGUES, A.M. Atividade turística e transformação territorial: discurso e ação do Estado no Pantanal - MS. In: GERARDI, L.H.O.; MENDES, I.A. (org.). Teoria, técnica, espaços e atividades: temas de geografia contemporânea. Rio Claro: PPG/Unesp; AGETEO, 2001.

MORETTI. E.C. Atividade turística: produção e consumo do lugar Pantanal. In. BANDUCI JR. A.; MORETTI. E.C. (org). Qual Paraíso? Turismo e Ambiente em Bonito e no Pantanal. São Paulo. CHRONOS. Campo Grande. UFMS. 2001.

OURIQUES, H.R. A produção do turismo: fetichismo e dependência. Campinas. SP. Alínea, 2005.

PELLIN, V. Turismo no espaço rural como alternativa para o desenvolvimento local sustentável: estudo de caso. In: PORTUGUEZ. A. P. (org) et al. Turismo no espaço rural: enfoque e perspectivas. São Paulo. ROCA. 2006.

PEREIRA, L.C.B. Desenvolvimento e crise no Brasil 1930-1983. 16 ed., São Paulo: Brasiliense, 1985.

PORTUGUEZ, A.P. Agroturismo e Desenvolvimento Regional. São Paulo. HUCITEC. 2002.

PORTUGUEZ, A.P. et al. Turismo no espaço rural: enfoque e perspectivas. São Paulo. ROCA. 2006.

RODRIGUES. A.M. Desenvolvimento sustentável e atividades turísticas. In: RODRIGUES, A.B. (org.) Turismo Desenvolvimento Local. 2 ${ }^{a}$ Ed. HUCITEC. São Paulo, 2000a.

RODRIGUES. A B. Turismo local: oportunidades para inserção. In: RODRIGUES, A.B. (org.) Turismo Desenvolvimento Local. 2ª Ed. HUCITEC. São Paulo, 2000.

RODRIGUES, A.B. Turismo e Espaço: Rumo ao Conhecimento Transdisciplinar. São Paulo: HUCITEC, 1997.

RODRIGUES, A.B. (org.) Turismo Rural. São Paulo, Contexto, 2001.

RODRIGUES, A.B. Turismo rural no Brasil: ensaio de um tipologia. In: RODRIGUES, A . B.(org.) Turismo Rural. São Paulo, Contexto, 2001.

SILVA. J. G. Turismo em áreas rurais: suas possibilidades e limitações no Brasil. In: ALMEIDA, J.A.; FROEHLICH, J.M. e RIEDL, M. (orgs.) Turismo Rural e Desenvolvimento Sustentável. Campinas-SP: Papirus, 2000.

SILVA, B.C., CANTEIRO D.G.; SILVA, F.J. Da terceira para a melhor idade: um estudo de qualidade de vida e turismo. Caso: Centro de Convivência do Idoso Monte Castelo - Campo Grande - MS. Monografia.Turismo. Aquidauana - MS. 2005

SOUZA, M.J.L. Como pode o turismo contribuir para o desenvolvimento local? In: RODRIGUES, A. B. (org.) Turismo Desenvolvimento Local. 2ª Ed. HUCITEC. São Paulo, 2002. 
Marcos Pereira Campos: Universidade Federal do Mato Grosso do Sul, Aquidauana, MS, Brasil.

E-mail: mboteteu@hotmail.com

Link para o currículo Lattes: http://lattes.cnpq.br/3468672075977191

Milton Augusto Pasquotto Mariani: Universidade Federal do Mato Grosso do Sul, Campo Grande, MS, Brasil.

E-mail: miltmari@terra.com.br

Link para o currículo Lattes: http://lattes.cnpq.br/0935409945176042

Rosângela Custódio Cortez Thomaz: Universidade Estadual Paulista "Júlio de Mesquita Filho", Rosana, SP, Brasil.

E-mail: rothomaz@gmail.com

Link para o currículo Lattes: http://lattes.cnpq.br/9063800080265540

Data de submissão: 30 de junho de 2016

Data de recebimento de correções: 15 de julho de 2016

Data do aceite: 16 de agosto de 2016

Avaliado anonimamente 